\title{
Estrategias de reproducción matrimonial de la élite económica en Chile ${ }^{1}$
}

\author{
Sebastián Huneeus*
}

\begin{abstract}
Resumen
Por medio de doce entrevistas en profundidad y análisis de discurso se describen algunas de las condiciones objetivas y subjetivas de la afinidad interpersonal de la élite. Las conclusiones apuntan a que el sistema de afinidad se basa en preferencias y restricciones matrimoniales $y$, por otro lado, que existe un proceso de cierre y de apertura que explica la renovación parcial de este grupo.
\end{abstract}

Palabras claves: Élite - cierre social - estrategias matrimoniales.

\begin{abstract}
By means of twelve in depth interviews and discourse analysis, some of the objective and subjective conditions that explain the interpersonal affinity of the élite are described. The conclusions argue how the system of affinities is based upon marriage restrictions and preferences and, secondly, that there is a process of social closure and aperture that explains the structure of the partial renewal of this group.
\end{abstract}

Keywords: Elite - social closure - marriage strategies.

1 Para profundizar más sobre el tema véase el libro de Sebastián Huneeus (2013): Matrimonio y patrimonio, Uqbar Editores, Santiago de Chile.

* Sociólogo de la Universidad de Chile y MSc en Sociología Económica de la London School of Economics. Ha participado en el proyecto ICSO-UDP sobre élites económicas a cargo de José Ossandón. 


\section{INTRODUCCIÓN}

En La élite del poder, Wright Mills abonó el territorio para el estudio de las élites económicas desde una perspectiva de redes. Habiendo definido a la élite económica como funcionalmente diferenciada a partir de la disociación entre propiedad y control, pero estratégicamente vinculada a través de intereses comunes y redes de directorio y de propiedad, su mirada fue crucial para entender que "La 'diseminación' de la gran propiedad tiene lugar dentro de un círculo muy pequeño (...) sus intereses llegan a vincularse con los de la clase corporativa en general“ (Wright Mills, 2005: 119-120). Llevado al terreno de las redes económicas, el análisis de las redes de directorio y propiedad sirve para desarrollar lo que John Scott $(1997,2008)$ considera como el control por medio de una "constelación de intereses", definida como un contexto dominado por un número limitado de accionistas minoritarios que se relacionan logrando tener un control indirecto sobre un vasto grupo de organizaciones. Dentro de esta línea es necesario notar que "Los entrelazamientos ocurren entre organizaciones, pero son creados por individuos" (Mizruchi, 1996: 277). En este campo, Zajac (1988) argumentó que la participación en directorios responde a las expectativas de los ejecutivos de aumentar su prestigio, redes y oportunidades de negocios.

Habiendo brevemente definido a la élite económica como un conjunto de actores dentro de una red de posiciones de poder económico, ¿qué se sabe, sociológicamente, sobre las élites económicas en Chile? Se sabe que Chile es una sociedad altamente estratificada (Torche y Wormald, 2007), con élites cohesionadas y diferenciadas respecto del resto de la sociedad (PNUD, 2004), y con mecanismos efectivos de reproducción social (Revista Capital, 2003). Desde el punto de vista de su reproducción social, se ha atendido a su hábitus aristocrático (Stabili, 2003), a su ethos religioso (Thumala, 2007) y a sus mecanismos de cierre social (Aguilar, 2011). Desde un punto de vista analítico-formal hay investigaciones que han observado a la conformación de las élites políticas, por ejemplo, a través del análisis de redes sociales (Espinoza, 2008). Pese a los cambios en la composición del empresariado, es posible sospechar la existencia de redes parentales a nivel de la élite económica (Núñez y Gutiérrez, 2004). Existe evidencia que demuestra que las principales empresas que cotizan en la Bolsa en Chile son conglomerados familiares (Lefort y Walker, 1999). No obstante, no es mucho lo que se ha avanzado en el plano del estudio de las redes económicas.

Analizar las estrategias de reproducción de la élite chilena, por tanto, implica asumir que todo matrimonio conlleva patrimonio, lo que dicho en clave sociológica equivale a decir que la trayectoria vital está determinada por el traspaso de activos de una generación a otra (Cepal, 2010; PNUD, 2010). En la tesis de pregrado Las estrategias matrimoniales de la élite económica chilena (Huneeus, 2010, 2013), realizada en el marco del Proyecto Desigualdades, se abordó en forma cualitativa el modo en que personas de clase alta se enlazan matrimonialmente. Por medio de doce entrevistas en profundidad semiestructuradas, los informantes otorgaron una serie de descripciones de su grupo de pertenencia y de las condiciones de posibilidad de la reproducción matrimonial de este grupo. El ánimo de dicho trabajo fue el de indagar sobre los mecanismos que permiten la reproducción grupal de quienes ocupan las posiciones de máximo poder económico en Chile. 


\section{ANTECEDENTES HISTORIOGRÁFICOS}

Como ha señalado el historiador Jocelyn-Holt a propósito de las raíces históricas de la estructura social en Chile, es en la sociedad hacendal, y en sus modos de sociabilidad, de donde se desprende la explicación para algunos de los fenómenos del presente: "Precisamente, fue en estos caseríos tempranos, aún precarios, donde se fraguó un orden social con aspiraciones del todo envolventes. Fue allí donde surgió la sociedad que hasta hace poco persistía en Chile" (Jocelyn-Holt, 2008: 138).

Respecto de los matrimonios, la revisión de algunos antecedentes históricos sobre la élite tradicional permite diseñar una plataforma de reflexión sobre el fenómeno de los lazos matrimoniales, la que combinó la endogamia con la cooptación de nuevos miembros que pudiesen aportar la reproducción social de las familias troncales. A riesgo de constituir un modelo, el esquema constituye más bien una construcción de tipos que sirven para observar algunos datos históricos. En primer lugar, existe evidencia de prácticas matrimoniales endogámicas, es decir, de matrimonios entre parientes lejanos que pertenecían a la élite. Manuel Vicuña señaló que la endogamia se dio con holgura en las familias de la élite, al extremo de practicarla, según refiere un testimonio de mediados del siglo XIX, "entre los grados prohibidos de la consanguinidad" (Vicuña, 2001: 64). O como dice el historiador de la Universidad de Chile, "Establecer vínculos de compadrazgo con miembros de la misma familia, acordar matrimonios endogámicos, estimular el matrimonio con cuñadas viudas a fin de evitar el retorno de las dotes" (Jocelyn-Holt, 1999: 91), eran estrategias sociales legitimadas durante el período colonial, que permitían la circulación de recursos y oportunidades al interior de un círculo social acotado por relaciones de parentesco.

Sin embargo, producto del desarrollo comercial y la apertura política en el período republicano, comenzaron a amalgamarse algunas de las familias tradicionales con la emergente burguesía compuesta por comerciantes inmigrantes, por mineros chilenos o extranjeros y por militares (Villalobos, 2006). Como dice Mario Góngora (2006), a fines del siglo XIX la élite dirigente nacional había sufrido importantes variaciones producto del acceso de fortunas emergentes en la dirección del Estado. La consolidación de una burguesía nacional con características aristocráticas se remonta a este período, en el cual las viejas familias hacendadas del período colonial se entremezclaron con las ya mencionadas familias ascendentes a través de los negocios, la política y el ejército del período portaliano. Ciertamente, esto tuvo un correlato a nivel de las estrategias matrimoniales, siendo, por tanto, posible trazar otro tipo de estrategias matrimoniales tendientes a reforzar económicamente a las familias de la élite ya asentadas, incorporando a nuevos miembros enriquecidos e incorporándose nuevos apellidos y culturas en las capas superiores. Un ejemplo de este tipo de apertura matrimonial está documentada por la socióloga de la Universidad de Chile Silvia Lamadrid, en su estudio titulado Los médicos en las redes de poder en el siglo XIX (Lamadrid, 2007).

Rovira (2011) y Vicuña (2001) señalan que en la bèlle epoque chilena a comienzos del siglo XX, producto del crecimiento de las riquezas y del contacto con Europa, se 
dieron matrimonios entre viejas familias de la independencia de Chile y comerciantes, banqueros e industriales mineros (Vicuña, 2001). Respecto de ese momento, cabe traer a colación un ejemplo de restricción matrimonial; durante el siglo XX hubo árabes que fueron rechazados por la élite por transgredir el statu quo de la élite santiaguina demostrando, con ostentación, riquezas que debían ser llevadas con más sobriedad (Stabili, 2003: 239). Esto, según señala la historiadora, constituyó una de las restricciones matrimoniales de la élite tradicional: el recelo a la incorporación de los "recién llegados" a la clase alta cuando no se comportaban de acuerdo con su hábitus aristocrático (Stabili, 2003: 240).

Para mediados del siglo XX, la élite tradicional concentraba el poder económico. Como respuesta, fueron dos sociólogos norteamericanos, Zeitlin y Ratcliff (1988), quienes por primera vez examinaron las redes de propiedad y control a nivel de las principales corporaciones financieras, corporaciones no financieras y propiedades agrícolas de Chile en el año 1965, estableciendo un sistema de relaciones que denominaron como "kinecon group" ${ }^{2}$. Uno de los hallazgos de los sociólogos fue el análisis de la figura del "capitalista financiero", entendida como el actor económico que se sienta simultáneamente en el directorio de uno de los cinco grandes bancos y en una de las 37 principales corporaciones no financieras. Sobre este tema señalaron los autores que existen los capitalistas financieros de primera línea, que son lo que se podría denominar el "núcleo duro" del empresariado chileno al año 1965. Así, al menos en Chile, los capitalistas financieros "virtualmente personifican la fusión de familia y propiedad al interior del ámbito burocrático e interorganizacional de la gran corporación" (Zeitlin y Ratcliff, 1988: 139), quienes además estaban emparentados con las familias terratenientes.

Los análisis históricos revelan que los matrimonios de la élite y, por tanto, sus estructuras parentales, ayudaron a darle cierta estabilidad como grupo que, complementada con el ejercicio de funciones políticas, militares y económicas, hicieron de la élite tradicional un fenómeno histórico de larga duración en el país. Según los analistas, la razón por la cual este grupo sobrevivió es porque siempre estuvo abierto a incorporar a los nuevos miembros, a los individuos emergentes, con la condición de que aportara con algún capital económico, político o cultural. Gracias a esto, familias inmigrantes, generalmente europeas, fueron consolidando un grupo aristocrático-burgués compuesto por apellidos españoles, ingleses, alemanes, franceses e italianos principalmente. Para la actualidad no existen antecedentes sistemáticos sobre los matrimonios de la élite y su vinculación con los negocios. No obstante, existe material de reciente circulación sobre la conformación cultural sobre grupos de clase alta en la sociedad chilena.

2 Kinecon es un neologismo que se compone del prefijo "kin", proveniente de "kinship" ("parentesco" en inglés) y de la terminación "econ", proveniente de "economic" "economía" en inglés). Por esta razón, para el análisis de la clase dominante chilena los autores plantean que "La gran corporación (y también, los grandes bancos) está controlada, en suma, por lo que hemos designado como un 'kinecon group', una unidad social compleja en que intereses económicos comunes y relaciones de parentesco comunes son indisolubles" (Zeitlin y Ratcliff, 1988: 7). 


\title{
III. ANTECEDENTES SOCIOLÓGICOS
}

Recientemente, el libro editado por Alfredo Joignant y Pedro Güell, Notables, tecnócratas y mandarines (2011), fue recibido con gran efusión, ya que entrega nuevos elementos para una sociología de las élites en Chile. Para el tema de las élites económicas y su reproducción, el trabajo de Omar Aguilar (2011) en el libro ofrece una interpretación de las pautas de cierre social de la élite con base tradicional y sus estrategias de distinción. El trabajo ahonda sobre tres fronteras sociales, una frontera de carácter moral, otra económica y, por último, una frontera cultural. Interesante es rescatar su noción de frontera moral, la que a juicio del sociólogo constituye uno de los elementos centrales de la élite económica con base tradicional de hoy y, probablemente, una de las fronteras más difíciles de traspasar. Como dice Aguilar, citando a una entrevistada:

\begin{abstract}
"Quizás la idea más recurrente en el discurso de la élite tradicional sea la que identifique a la élite como gente buena. Uno se ubica 'al tiro' con la gente y eso naturalmente te da cierta tranquilidad. Si el hijo de una se va a casar con una persona que tú más o menos ubicas a la familia, quienes son, que historia tienen, son gente buena, son gente honrada, son gente honorable, ¡mira qué bueno!" (Aguilar, 2011: 233).
\end{abstract}

Aguilar postula que la frontera moral es la que distingue entre gente buena (el "nosotros") y la gente común (el "ellos"), y concluye dando una interpretación de alto interés sociológico: que las fronteras de carácter cultural (credenciales educacionales) y económicas son más permeables que las de carácter moral, siendo esta última la frontera de mayor rigidez ya que sirve, entre otras cosas, para distanciar a los "viejos" de los "nuevos ricos" a través del sentido de la austeridad y de la vocación de servicio público que se hereda intergeneracionalmente a través de vínculos parentales.

El trabajo de Angélica Thumala es en cierta medida concordante con el trabajo de Aguilar, no obstante su definición de élite apunta a los altos ejecutivos de grandes empresas que practican la religión católica -no a una élite de base tradicional-. Su análisis, también inspirado en parte por la obra de Bourdieu, parte de la base de que "las preferencias éticas y el comportamiento inspirado en la religión pueden ser importantes fuentes de prestigio" (Thumala, 2011: 185) o, en otras palabras, de distinción. Según la autora, la reapropiación del catolicismo de parte de la élite económica chilena está inspirada en un intento por redefinir las fronteras sociales en base a un tipo de catolicismo que juega un rol importante en la identidad de sus miembros, de sus preferencias de trabajo, de educación de sus hijos y en el concepto bajo el cual se piensa que se debe conducir la economía. Independientemente de si la espiritualidad de la élite económica sea genuina o no, el trabajo de Thumala abre la pregunta sobre cómo la apropiación del catolicismo de parte de la élite económica puede estar respondiendo a la lógica del espacio social, es decir, a pugnas por la monopolización de posiciones de jerarquía y de distinciones al interior de campos.

Por último, el trabajo de Cristóbal Rovira (2011) contiene una crítica a algunos de los aportes de Bourdieu para una sociología de la reproducción social. De su análisis, que entrega una serie de elementos para una sociología histórica de las élites latinoamericanas, se rescatan 
los siguientes. En primer lugar, que la teoría de la reproducción de Pierre Bourdieu no resulta tan adecuada para comprender períodos históricos de larga duración que han dado forma a las élites latinoamericanas, ya que las élites criollas se han constituido gracias a paulatinos procesos de renovación y reemplazo. En segundo lugar, que la teoría de la reproducción de Bourdieu sí resulta pertinente para comprender los procesos de clausura social como, por ejemplo, la bèlle epoque chilena ya mencionada. En suma, del trabajo de Rovira se desprende que la sociología de Bourdieu es poco ecuánime, ya que mira excesivamente a los procesos de clausura social, siendo que las élites, según la concepción de Pareto y de Mosca, se van consolidando gracias a un proceso paulatino de clausura y de circulación social.

Los tres antecedentes convocados por Güell y Joignant permiten un acercamiento a una sociología de las élites económicas en Chile, no obstante, no constituyen un análisis de las estrategias gregarias del empresariado para consolidar posiciones de poder. Sin embargo, permiten conformar un cuadro acerca de cómo la élite genera pautas de distinción y fronteras sociales entre las cuales se pueden enmarcar intercambios matrimoniales.

\section{ESTRATEGIAS MATRIMONIALES}

Considerando que el matrimonio constituye un eslabón dentro de la reproducción social, cabe hacer una precisión que se refiere al alma de nuestra investigación, el rapport. Durante las entrevistas, muchos entrevistados demostraron cierta reserva a la hora de hablar del carácter estratégico del matrimonio; esto se debió a que existen escrúpulos a la hora de revelar cosas tan personales frente a un investigador más o menos anónimo para ellos. Por tanto, nuestra aproximación al fenómeno fue por medio de la descripción de las condiciones que explican la afinidad interpersonal antes que indagar directamente sobre la estructura misma de los matrimonios; por ello, bastante material está más centrado en las autodescripciones de la élite antes que en un análisis pormenorizado de sus lazos conyugales. No obstante, a la luz de la cantidad de material que existe reafirmando el carácter cerrado y endogámico de los grupos privilegiados en Chile, esto no fue considerado como una debilidad sino que más bien una forma levemente diferente para explicar las condiciones de la afinidad interpersonal.

Señala Bourdieu que "Las estrategias matrimoniales (...) deben asegurar la reproducción biológica del grupo sin amenazar su reproducción social por un mal matrimonio y contribuir, por la alianza con un grupo al menos equivalente bajo todas las relaciones socialmente pertinentes, al mantenimiento del capital social" (Bourdieu, 2002: 6). Si esto se combina con lo planteado por Rovira (2011), el análisis de las estrategias matrimoniales debe explicar la afinidad interpersonal tomando en cuenta que en las élites existen simultáneamente procesos de cierre social y de circulación. Hay cierre social en la medida en que existen barreras matrimoniales y hay circulación en tanto que los matrimonios no son totalmente endogámicos, permitiéndose la renovación y fusión del capital social. Además, los matrimonios son producto de afinidades que se establecen en el plano material y subjetivo. Así, en el emparejamiento confluyen intereses económicos e identidades culturales. Por esto es que Bourdieu señala, al igual que los entrevistados, que las estrategias matrimoniales constituyen 
estrategias de reproducción social que no necesariamente están ligadas a una decisión racional, pues no son puramente económicas. Por esta razón, el análisis de las estrategias matrimoniales debe considerar que si bien existen preferencias matrimoniales, también existe algo misterioso denominado "amor romántico" en que el azar, la libertad y el error juegan un papel importante.

En suma, pese a padecer cierto déficit en el rapport, los informantes se atrevieron a entregar muchos datos y opiniones sobre lo que son las condiciones de posibilidad de la afinidad interpersonal de la élite. Pese a que esto puede ser una debilidad de nuestro diseño de investigación, si es un insumo valioso para el análisis cualitativo de las condiciones que explican la afinidad material y subjetiva de los miembros de su grupo.

\section{ESTRATEGIAS MATRIMONIALES DE LA ÉLITE}

Las entrevistas revelaron que los matrimonios no se dan en un universo libre de normas, lo que demuestra que las uniones conyugales dependen en un grado de algunas instancias que formatean la afinidad interpersonal. Los sentimientos de afinidad, por tanto, se deben analizar considerando las condiciones que la definen como tal.

La ceremonia matrimonial es el signo externo y más estético de reproducción de la élite, pero evidentemente la ceremonia simboliza cosas de fondo, específicamente, un enlazamiento conyugal en la cual está comprometida la reproducción biológica y socioeconómica de un grupo. Pues bien, invariablemente los entrevistados reconocieron que el matrimonio ha sido y es una forma importante de reproducción social:

“(La élite) se reproduce a través del matrimonio, siempre. (...) Estas niñitas, que estudian educación en la de Los Andes o en la Católica, las casas con un ingeniero de la de Los Andes o de la Católica, que han vivido en mundos más o menos cerrados, más o menos protegidos, y lo más probable es que no hayan problemas" (Antropólogo, soltero, 25 años).

"Una de las maneras de cuidar patrimonio de las élites tiene que ver con los matrimonios. Me atrevería a decir que mientras mayor nivel de ingreso, mayor es la tasa de matrimonio, o mientras mayor el patrimonio, mayor es la tasa de matrimonio" (Propietario de firma de banca de inversión, casado exogámico, 55 años).

Cuando los matrimonios de la élite se dan seguidamente entre un circuito acotado de familias, aparece un componente de casta que se explica, por ejemplo, a través del complicado juego de apellidos que manejan algunos de los portavoces de estas familias -los que llegan a ser expertos en árboles genealógicos-. La élite tiene características de casta, que se evidencia externamente por la mención a consideraciones simbólicas en torno a los apellidos.

La importancia estratégica que tienen los matrimonios se ve reflejada en un proceso doble: la élite enfrenta un proceso de cierre y de circulación social, que se ve respaldada a través de sus estrategias matrimoniales. Hoy en día los matrimonios se dan tanto entre personas genealógicamente vinculadas como sin vinculación previa, siendo común ver el matrimonio entre personas lejanamente emparentadas, así como entre personas no 
relacionadas previamente. $\mathrm{Al}$ respecto, hubo variados testimonios que globalmente ayudan a sostener la tesis de que existe circulación matrimonial al interior de la élite:

"En la élite chilena, los matrimonios, en general, son bien abiertos, ¿te fijas tú? Claro, hay casos que evidentemente uno podría decir 'la antigua fronda se reproduce'. Pero yo diría que son más bien marginales desde el punto de vista de la importancia social" (Abogada, casada endogámica, 60 años).

Esta declaración, no obstante, se vio continuamente matizada con su opuesto; así como se revela circulación familiar al interior de la élite, también hay espacios en que esa circulación se ve restringida:

"Me tocó ver en esos círculos a personas con apellido, personas con poder económico muy fuerte y que sí tendían a no salirse de eso. Que los apellidos con doble erre tendían a juntarse o cosas de ese tipo" (Ingeniera comercial, soltera, 30 años).

“El apellido pesa, crea una especie de aureola de respeto y admiración. Muy pocos son los que se absolutamente desprenden de esa característica (...) A la mayoría les encanta tenerlos y les encantaría casarse con quien los tenga" (Abogado, casado endogámico, 65 años).

Lo anterior indica que los espacios de formación y convivencia de la élite están abiertos a circulación, aunque, paradójicamente, tengan cierto grado de cierre social. Esto lleva a considerar que la existencia de condiciones que favorecen la circulación de la élite, no obstante las rígidas fronteras sociales que separan a la élite del resto de la sociedad, es un tema que siempre salió a flote durante las entrevistas. Una muestra clara de las fronteras explícitas son las barreras de admisión a los clubes de la élite, como el Club de Golf Los Leones, el Club de Golf Las Rocas de Santo Domingo y los clubes de polo, a los que hay que postular pagando una elevada suma y además venir patrocinado por miembros que ya tengan cierta antigüedad en el mismo club:

"Hay varios clubes de golf en este país, pero no le permiten la entrada a cualquiera, aunque tengas la plata. Tienes que aplicar por socios que ya existan. $Y$ hay gente, entonces, que ha decidido, por ejemplo como la colonia judía, hacer clubes de golf separados porque no los dejaban entrar al Sport Française, que es prototipo de lo que yo te estoy diciendo. Que es cerrado, no tiene acceso, no puedes llegar y permeabilizar" (Propietario grupo industrial, casado exogámico, 55 años).

En suma, desde el punto de vista de sus miembros, el matrimonio es clave para la reproducción socioeconómica de la élite; los matrimonios se enfrentan a un proceso de apertura y de cierre, aunque, finalmente, una fuerte barrera social cierre el acceso a este círculo a quienes no pertenecen a ella.

\section{AFINIDADES}

Los doce entrevistados coincidieron con la importancia que tienen los elementos materiales y subjetivos dentro de la conformación de un sistema de afinidades interpersonales. Dentro del plano material sobresalen la educación y el perfil profesional de estos miembros. En el 
plano subjetivo, sobresale la matriz valórica, por ejemplo, religión y política, así como el "modo de ser".

En el colegio se cimienta la base psicosocial, pero además se establece paridad, pertenencia en el plano subjetivo, cultural y social. Los colegios que se mencionaron fueron siempre privados y, generalmente, católicos. Cabe remarcar que a lo largo de todas las entrevistas se hizo especial hincapié sobre la importancia de los colegios católicos en la formación de los círculos sociales que se conservan a lo largo de la carrera profesional. Los doce entrevistados se refirieron a que los colegios religiosos vinculados al Opus Dei, a los Legionarios de Cristo y al Movimiento Apostólico de Schoenstatt están activa y conscientemente formando a los presentes y futuros líderes económicos de Chile. Como dijo una entrevistada perteneciente a este mundo:

"Yo creo que el éxito del (colegio) Tabancura tiene que ver con un montón de cosas, que tienen que ver con la formación de hábitos, con un cierto rigor, con una religiosidad..." (Abogada, casada endogámica, 60 años).

Esto se explica porque todos los entrevistados señalaron unánimemente que la élite es, en su conjunto, en menor o mayor grado, católica. Eso queda plasmado en el testimonio de un empresario y actual director de un colegio laico para la élite:

"Los colegios son los típicos, ya sean Opus Dei, Legionarios, schoenstattianos o jesuitas, con distintos matices pero se mueven en ese rango" (Director de colegio y de empresas, casado endogámico, 45 años).

Los doce entrevistados coincidieron plenamente en la importancia que tienen los colegios católicos y privados en la formación de los actuales y futuros miembros de la élite económica. Además, surgieron varias perspectivas sobre el perfil profesional de un típico miembro actual de la élite económica; se señaló que la formación universitaria, principalmente en derecho e ingeniería comercial; abre las puertas para acceder a estructuras de influencia económica. En todos los casos, este profesional típico es descrito como un ejecutivo que desempeña roles de control y/o propiedad, generalmente alcanzando la participación en los directorios de grandes empresas que pueden ser industriales, financieras o de servicios. Respecto de las tareas que cumplen estos miembros, un entrevistado precisó lo siguiente:

"El abogado yo creo que hoy día todavía tiene cierta respetabilidad, pero le gana el ingeniero comercial. Nunca lo había pensado así, pero la que actualmente está muy socialmente deteriorada es medicina" (Abogado, casado endogámico, 65 años).

El decaimiento del prestigio de la carrera de medicina es algo que también mencionaron otros entrevistados y se debe, principalmente, a que la élite económica cada vez desempeña tareas más gerenciales y administrativas. Respecto de la trayectoria de estudios de los profesionales de la élite, los entrevistados señalaron que es muy relevante dónde se lleva a cabo la formación profesional. Aquí de nuevo aparecieron las instituciones relacionadas con la Iglesia Católica, con el protagonismo de la Pontificia Universidad Católica de Chile, pero pisándole los talones instituciones como la Universidad de los Andes y la Universidad 
del Desarrollo. Pero además se habla de posgrados en economía, leyes o administración en el extranjero como si se tratara de una forma de consagración importante para ingresar al mundo de los negocios:

"Para llegar a tener esa seguridad (económica), tienes que hacer una especie de curso que ya está fraguado: entrar a ingeniería, administración de empresas en la Católica y salir a Chicago" (Historiador, 55 años).

A través de este perfil se observa que la élite ejerce mayormente tareas gerenciales y ejecutivas. Otro aspecto constitutivo del perfil de los miembros típicos de la élite económica es su "modo de ser". Esta es, probablemente, una de las variables que más explican la pertenencia a los círculos sociales de la élite económica, a la vez que es una de las más complejas de medir para los investigadores. Muchas de las dimensiones de este modo de ser son inconscientes y, por lo tanto, no alcanzan a tornarse reflexivas y verbalizadas en la conversación. El modo de ser abarca desde la corporalidad hasta las maneras de hablar, pasando por gustos y opciones subjetivas; a modo de sistema de símbolos, le demuestran al mundo la pertenencia a determinados espacios sociales. Una entrevistada, que proviene familiarmente de los estratos medios-bajos y está casada con un multimillonario del área de las finanzas, relató parte de su experiencia de vida al ingresar a círculos de élite:

"Cuando yo me casé con Juan Andrés, yo les contaba a sus amigos la historia del Liceo 530 y decían 'Qué simpática que es la Daniela' pero no me creían, y Juan decía 'Sí, es verdad'. Pero al final me han querido por lo que soy, pero tampoco soy una persona que hable mal y que tenga mala educación" (Propietaria, casada exogámica, 45 años).

Otra entrevistada señaló que:

"La polola de mi papá, sin ir más lejos. Ella nació en San Antonio, y es bien flaite. Onda que su papá habla de 'tú soy', te habla de la 'vienesa' y de que 'el perro se pisó a la perra'... ¿Cachai? Y después llega a la casa y toca la bocina pa' que la nana corra a abrirle la puerta. Y habla de que ella quiere vivir en La De-he-sa, y modula pa' que suene bien cuico..." (Diseñadora, casada exogámica, 30 años).

Dentro de la variedad de códigos que rigen y que denotan la pertenencia social a la élite están las normas de comportamiento en situaciones formales e informales, así como también en situaciones familiares y públicas. Un importante empresario hizo hincapié en la relevancia que tiene el manejo de códigos de conducta en el acceso a las altas jerarquías empresariales y de cómo esto afecta a la meritocracia:

"Tú puedes ser el tipo más genial del mundo, pero en este negocio nuestro de la banca de inversión, el tipo tiene que tener además una educación social. Porque se va a tener que entender al otro lado con gente que no va a tener una respuesta de confianza" (Propietario de firma de banca de inversión, casado exogámico, 55 años).

Por otro lado, según los doce entrevistados, existen rasgos ideológicos que caracterizan al miembro típico de la élite económica. Como ya se vio antes, es constituyente de su identidad una concepción católica del mundo, pero a esta habría que sumarle una visión derechista de 
la política. En algunos casos, la concepción religiosa y política resultan complementarias a través de posturas cercanas al conservantismo católico de la Unión Demócrata Independiente (UDI), partido político cercano al Opus Dei y a los Legionarios de Cristo. Sobre la participación política del empresariado, varios entrevistados coincidieron en lo mismo:

"La participación política de este movimiento está muy influida por los movimientos políticos de los sesenta en la (Pontificia Universidad) Católica. Resulta que han creado un partido, que tiene sus raíces profundas en el régimen militar, un partido que es bien 'popular'... bien curioso el fenómeno (...) Tienen algo del antiguo conservantismo social cristiano" (Abogada, casada endogámica, 60 años).

Y las identidades políticas y religiosas tienden a confluir:

"Yo te diría que esta élite social, perteneciente mayoritariamente a la derecha, por no decir toda, le interesa bastante la cosa pública. En el fondo para mantener privilegios y tener la certeza de que se va a mantener, en el fondo, el legado político de su gran inspirador, que es Jaime Guzmán" (Abogado, casado endogámico, 65 años).

No obstante, hay que poner en evidencia que existen opiniones matizadas entre algunos entrevistados:

"Si te hago una caricatura de esa élite, te diría que son estudiantes de derecho de la Universidad Católica, miembros del movimiento gremial, de las juventudes de la UDI y de las alas sumamente conservadoras religiosas" (Empresario y director de colegio, casado endogámico, 45 años).

No obstante los matices, el grueso de los discursos tendieron a coincidir en que ideológicamente la élite económica es católica y de derecha. Sobre la ideología política, no obstante entre los entrevistados no se hicieron menciones a la adhesión a Augusto Pinochet, sí a Jaime Guzmán, líder político e ideológico de los movimientos de derecha en el gobierno militar.

Por último, cabe señalar la importancia que se les asigna a los apellidos:

"El tema del apellido te marca la paridad. Bueno, hay por supuesto muchos apellidos que son absolutamente dispares; hay un montón de González de muchísima categoría. O sea, a veces, el apellido no significa nada: lo que significa es la familia" (Profesor y director de colegio, numerario Opus Dei, 75 años).

Los apellidos de familias conocidas son un tema al que los entrevistados siempre recurrieron para dar ejemplo sobre algún miembro de la élite o para referirse a fenómenos estructurales como la influencia de las familias castellano-vascas en el pasado y, en cierto grado, en la actualidad. A partir de ello, se colige que los apellidos pesan en la sociedad chilena. Se observa que en muchos sectores de la economía alguna familia antigua tiene algún representante:

"Yo creo que en este país las personas que tienen apellidos tradicionales tienden a acceder a un nivel de vida muy por encima al que hubieran accedido sin el apellido. Yo 
te aseguro que alguien que estudie en una no muy buena universidad, pero que tiene los apellidos, logra mucho más que uno que estudió en una mucho mejor universidad pero sin tener sus apellidos y su apariencia física" (Propietario grupo industrial, casado exogámico, 55 años).

Así, la importancia que se les asigna a los apellidos expresa que existen familias que gozan del pedigrí de tener poder económico, es decir, que han logrado convertir su capital económico en capital simbólico. La importancia de los apellidos también se revela en que los entrevistados siempre recurrieron a ellos para diferenciar a los "viejos" de los "nuevos" ricos, refiriéndose a los primeros cuando la conversación trataba sobre exponentes "genéticamente puros" de la élite económica:

“(El apellido) era un tema de conversación permanente de la mesa familiar; le hacían a uno un mapa permanentemente" (Historiador, 55 años).

“(El apellido) influye, porque a la gente le gusta pertenecer a ciertos mundos y diferenciarse de los demás" (Ingeniera comercial, soltera, 30 años).

Las características desarrolladas más arriba hablan de criterios que rigen la afinidad interpersonal. Esta descripción corresponde a una síntesis de las características generales de los individuos que ingresan y pertenecen al mundo de las altas influencias corporativas en Chile. Las categorías que más pesan, todas ellas nombradas por los entrevistados, son la educación, la posición económica y profesional, religiosidad e ideología política. Consideradas conjuntamente, aquí se está describiendo un cuadro en el que lo subjetivo y lo objetivo parece estar más o menos alineado, lo que favorece la estabilidad de este grupo.

\section{RESTRICCIONES MATRIMONIALES}

Para conocer las afinidades interpersonales es necesario también conocer las condiciones que limitan la afinidad, a saber, las restricciones. Considerando que, sin excepción, los entrevistados vieron en el matrimonio un mecanismo que ayuda a la consolidación de los grupos sociales y económicos de la élite, vale la pena revisar una de las normas más comunes que fueron apareciendo entre los entrevistados. La primera norma es la evaluación negativa hacia el matrimonio entre judíos y una élite económica que se autopercibe como de fe católica:

"Estoy pensando en uno, en uno de estos hijos de una familia de élite que no se había casado, que tiene mi edad, compañero mío de curso, que pololeaba con una niña judía. Y el comentario de la familia era 'súper amorosa la niñita, pero es judía'" (Director de colegio, casado endogámico, 45 años).

"Cuando se casó Juan Andrés con la Natalie, se decía que se casó pésimo porque era judía" (Propietaria, casada exogámica, 45 años).

Es una norma, no obstante, que ejerce cierta presión moral sobre los miembros de las familias católicas, ya que existe una preferencia por la homogeneidad social y cultural. Pareciera ser que lo que es sancionado es la unión de un miembro de una familia de condición judía 
con un miembro de una familia que es católica. Las razones de esta evaluación negativa no fueron desarrolladas en profundidad en la tesis, quedando abierto el tema para futuras investigaciones.

La segunda restricción abarca genéricamente a las formas de matrimonio que menoscaben el estatus del novio que pertenezca previamente a la élite; así, esta norma excluye a las clases medias en general, a los mandos medios, a los pueblos originarios $y$, en el fondo, a todos aquellos profesionales que no estén más o menos vinculados con el poder económico. Sobre las fronteras sociales, por ejemplo, una entrevistada entrega una opinión majadera al respecto:

"Santiago, en ese sentido, es tremendamente sectario y clasista. Creo que para una persona de una clase social diferente, que se casa con una persona del sector alto, nunca es verdaderamente recibida o acogida dentro de la clase social alta" (Gestora cultural, casada endogámica, 50 años).

Otra entrevistada, en cambio, relata su experiencia y molestia frente a uniones de amistades suyas con personas provenientes de estratos sociales inferiores:

"(Tengo) amigos que son salidos del Grange, multimillonarios, y una de sus hermanas está
pololeando con un huevón último, fresco, flojo, de pueblo... El Edwin. Que realmente no.
Y el otro hijo, también, con una niña de Viña, también promotora. Siendo que ellos son
absolutamente inteligentes: él ingeniero industrial y ella filósofa, ipero seca! Y tú dices
¡cómo!" (Diseñadora, casada exogámica, 30 años).

Las dos restricciones matrimoniales esbozadas son generalizaciones y bajo ningún concepto constituyen tabúes. De hecho, pueden ocurrir esos matrimonios, pero estos no reciben el mismo trato ni reconocimiento que los matrimonios endogámicos -que se dan entre miembros que pertenecen ya por familia a la élite-. Las restricciones operan como una sanción moral de parte de los miembros de la élite, las que se expresan en que las uniones entre cristianos y judíos tengan una menor probabilidad de suceder que entre miembros cristianos de los grupos dominantes -la misma generalización vale para los matrimonios hipogámicos, es decir, con familias de menor estatus-.

Por medio de la constitución de estas dos normas, a saber, pautas que tornan improbables las uniones entre grupos separados, más la configuración de principios de afinidad, se pueden establecer algunas conclusiones de carácter general en torno a las estrategias matrimoniales de la élite económica chilena.

\section{CONCLUSIONES}

Los matrimonios no responden necesariamente a reglas económicas ni a principios de interés material, antes bien, obedecen a principios de afinidad estructural y afectiva que tornan probable el acercamiento entre dos personas y sus respectivas familias. En este sentido, el objeto del presente artículo es fomentar la discusión en torno a las barreras de acceso, tanto económicas como culturales y simbólicas, a la élite. 
El principal problema que emerge de este trabajo son los elementos objetivos y subjetivos que rigen la afinidad de la élite. La reproducción matrimonial es fruto de la afinidad no mecánica entre elementos objetivos y subjetivos. Las estructuras objetivas son espacios que están regidos por criterios de selección de ingreso como colegios, universidades, empresas y clubes y, por el contrario, las estructuras subjetivas son los pensamientos e ideologías que pueden favorecer la atracción interpersonal.

Además, como se revisó, doce entrevistados, vinculados por un lado u otro a la élite económica, señalan que existe un juego de cierre y de apertura matrimonial que afecta a la reproducción de los grupos económicamente dominantes. Este sistema de cierre y apertura permite generalizar que existe un sistema matrimonial compuesto de dos grandes normas que rigen la generación de matrimonios. En primer lugar, existe un sistema de intercambios matrimoniales al interior de los miembros de la élite económica, que tiene alcance sobre todos aquellos individuos que son reconocidos como pertenecientes a la élite. En segundo lugar, existen las restricciones matrimoniales, es decir, las uniones que no son aceptables para la élite. De esto se desprende que existan uniones consideradas desventajosas y que, por tanto, son objeto de sanción, como las uniones matrimoniales entre católicos y judíos, y con individuos que no pertenecen a la élite en general porque no han frecuentado los espacios más característicos en que se funda el roce social al interior de los grupos privilegiados.

Finalmente, cabe concluir proponiendo un concepto de élite económica para el caso chileno. La pertenencia a la élite está marcada por un doble ascendente: por un lado, tiene un ala moderna, que asigna posiciones a sus miembros según su lugar en la estructura económica (patrimonial y profesional), pero por otro lado tiene un ala conservadora, que asigna valoraciones sociales según el concepto de familia a la que se pertenece y el grado y tipo de religiosidad que se practica. En cualquier caso, posición económica, familia y religiosidad son fenómenos esencialmente gregarios; esto refuerza el hecho de que se llega a la élite en grupo y se refuerzan los lazos en ella mediante alianzas con otros grupos. Por esta razón, es necesario dejar de indagar a la élite únicamente en cuanto fenómeno económico; antes bien, hay que averiguar sobre su carácter gregario para ir descubriendo cómo familia, economía, educación, política y religión están vinculadas en una maraña de lazos que se yuxtaponen.

\section{BIBLIOGRAFÍA}

Aguilar, Omar (2011): “Dinero, educación y moral: el cierre social de la élite tradicional chilena", en A. Joignant y P. Güell (eds.): Notables, tecnócratas y mandarines. Elementos de sociología de las élites en Chile, 1990-2010, Ediciones Universidad Diego Portales, Santiago.

Bourdieu, Pierre (2002): "Estrategias de reproducción y modos de dominación", Colección Pedagógica Universitaria, 37-38.

CEPAL (2010): “Panorama social de América Latina 2010”, CEPAL, Santiago.

Espinoza, Vicente (2008): Mapa de las redes de poder en el seno de la élite política chilena desde el retorno de la democracia. El caso de los diputados (1990-2005), ponencia presentada en el congreso "Ciencias, tecnologías y culturas. Diálogo entre las disciplinas del conocimiento. 
Mirando al futuro de América Latina y el Caribe", Universidad de Santiago, 30 octubre-2 noviembre.

Góngora, Mario (2006): Ensayo histórico sobre la noción de Estado en Chile en los siglos XIX y XX, Editorial Universitaria, Santiago.

Huneeus, Sebastián (2010): Las estrategias matrimoniales de la élite económica chilena, Tesis para optar al Título Profesional de Sociólogo, Universidad de Chile.

(2013): Matrimonio y patrimonio: las estrategias matrimoniales de la élite económica chilena, Uqbar Editores, Santiago.

Jocelyn-Holt, Alfredo (1999): La independencia de Chile. Tradición, modernización y mito, Planeta Ariel, Santiago.

(2008): Historia general de Chile. Tomo III: Amos, señores y patricios, Editorial Sudamericana, Santiago.

Lamadrid, Silvia (2007): Los médicos en las redes de poder en el siglo XIX, trabajo de investigación inédito realizado para el curso "Los círculos del poder: redes y estrategias sociales en Chile y América Latina", impartido por el profesor Juan Cáceres en la Universidad de Chile.

Lefort, Fernando y Eduardo Walker (1999): “Ownership and capital structure of Chilean conglomerates: facts and hypotheses for governance", Revista Abante, 3 (1), pp. 3-27.

Mizruchi, Mark S. (1996): "What do interlocks do? An analysis, critique, and assessment of research on interlocking directorates", Annual Review of Sociology, 22, pp. 271-298.

Núñez, Javier y Roberto Gutiérrez (2004): “Classism, discrimination and meritocracy in the labour market: the case of Chile", Documento de Trabajo, 208, Departamento de Economía, Facultad de Ciencias Económicas y Administrativas, Universidad de Chile.

PNUD (2004): Informe de Desarrollo Humano: El poder, ¿ para qué y para quién?, PNUD, Santiago.

(2010): Informe regional sobre desarrollo humano para América Latina y el Caribe 2010. Actuar sobre el futuro: romper la transmisión intergeneracional de la desigualdad, PNUD, San José, Costa Rica.

Revista Capital (2003): "El club de la desigualdad", n¹03, 23 de mayo-5 de junio.

Rovira, Cristóbal (2010): “Hacia una sociología histórica sobre las élites en Latinoamérica: un diálogo crítico con la sociología de Pierre Bourdieu", en A. Joignant y P. Güell (eds.): Notables, tecnócratas y mandarines. Elementos de sociología de las élites en Chile, 1990-2010, Ediciones Universidad Diego Portales, Santiago.

Scott, John (1997): Corporate business and capitalist classes, Oxford University Press, London. (2000): Social network analysis, Sage, London.

Stabili, María Rosaria (2003): El sentimiento aristocrático: élites chilenas frente al espejo (1860-1960), Editorial Andrés Bello, Santiago.

Thumala, María Angélica (2007): Riqueza y piedad: el catolicismo de la élite económica chilena, Debate, Buenos Aires.

(2011): “Distinciones de base religiosa en la élite económica chilena: algunas limitaciones en el enfoque de Bourdieu", en A. Joignant y P. Güell (eds.): Notables, tecnócratas y mandarines. Elementos de sociología de las élites en Chile, 1990-2010, Ediciones Universidad Diego Portales, Santiago. 
Torche, Florencia y Guillermo Wormald (2007): “Chile, entre la adscripción y el logro", en R. Franco, A. León y R. Atria (eds.): Estratificación y movilidad social en América Latina: transformaciones estructurales de un cuarto de siglo, Editorial LOM, Santiago.

Vicuña, Manuel (2001): La belle epoque chilena: alta sociedad y mujeres de élite en el cambio de siglo, Sudamericana, Santiago.

Villalobos, Sergio (2006): Origen y ascenso de la burguesía chilena, Editorial Universitaria, Santiago.

Wright Mills, Charles (2005): La élite del poder, Fondo de Cultura Económica, México.

Zajac, E. J. (1988): "Interlocking directorates as an interorganizational strategy: a test of critical assumptions", Academy of Management Journal, 31 (2), pp. 428-438.

Zeitlin, Maurice y Richard Earl Ratcliff (1988): Landlords and capitalists: the dominant class of Chile, Princeton University Press, Princeton.

Recibido: 05-03-2012

Aceptado: 23-04-2013 